\title{
Correction to: Systematic review and meta- analysis of tick-borne disease risk factors in residential yards, neighborhoods, and beyond
}

Ilya R. Fischhoff ${ }^{1 *}$, Sarah E. Bowden ${ }^{1,2}$, Felicia Keesing ${ }^{3}$ and Richard S. Ostfeld ${ }^{1}$

\section{Correction to: BMC Infect Dis (2019)19:861 \\ https://doi.org/10.1186/s12879-019-4484-3}

Following publication of the original article [1], one of the authors, Dr. Sarah E. Bowden reported that at the time of the study she wasn't working for the Division of Global Migration and Quarantine, Centers for Disease Control, 1600 Clifton Road, Atlanta, GA 30329-4027, USA. The institution should be removed from the Author details section.

\section{Author details \\ ${ }^{1}$ Cary Institute of Ecosystem Studies, 2801 Sharon Turnpike, Millbrook, NY 12545, USA. ${ }^{2}$ Eagle Medical Services, LLC, 2835 Brandywine Rd. Suite 200, Atlanta, GA 30341, USA. ${ }^{3}$ Bard College, PO Box 5000, Annandale-on-Hudson, New York 12504, USA.}

Published online: 05 December 2019

\section{Reference}

1. Fischhoff IR, et al. Systematic review and meta-analysis of tick-borne disease risk factors in residential yards, neighborhoods, and beyond. BMC Infect Dis. 2019;19:861. https://doi.org/10.1186/s12879-019-4484-3.

Full list of author information is available at the end of the article 